\title{
Implementasi Metode SCOR 11.0 dalam Pengukuran Kinerja Supply Chain Management
}

\author{
Indah Permata Wulandari*, Wahyu Lestari Setyaningsih, \\ Aldo Prabu Wisnu Wardhana, Yuwan Jumaryadi \\ Program Studi Sistem Informasi, Fakultas Ilmu Komputer, Universitas Mercu Buana, \\ Jl. Raya Meruya Selatan, Kec. Kembangan, Daerah Khusus Ibukota Jakarta 11650 \\ *e-mail:41816120100@student.mercubuana.ac.id
}

(received: 4 November 2020, revised: 12 Desember 2020, accepted: 29 Desember 2020)

\begin{abstract}
Abstrak
Konsep kegiatan utama SCM ialah fokus pada proses pengiriman dan pengadaan barang. Studi kasus telah dilakukan sebelumnya, menggunakan metodologi Value Chain Analyst (VCA). Bagaimanapun juga terdapat beberapa permasalahan pada studi sebelumnya seperti analisis kepuasan pelanggan dan diakhiri dengan peningkatan rantai nilai pasokan. Untuk mengatasi masalah tersebut, kami mengusulkan untuk menggunakan Supply Chain Operations Reference (SCOR) untuk mengatur tingkat kinerja manajemen dan manajemen rantai pasokan. Tujuan dari penelitian ini adalah untuk mengetahui gambaran kinerja supply chain management dan tingkat kinerja supply chain management pada PT Nieve Aplikasi Mandiri, yang diukur dengan menggunakan pendekatan supply chain operation reference (SCOR). Langkah-langkah yang dilakukan dalam penelitian yang berbasis pada metode SCOR ialah, pertama pembobotan tingkat pada kepentingan indikator SCOR. Kedua, mengkategorikan tingkatan indikator kinerja SCM. Hasil dari penelitian menunjukan bahwa pengiriman dan pengadaan dengan menggunakan metrik metode SCOR level 1 dimana hasil yang diperoleh ialah Perfect Order Fullfillment $(P O F)=72.28 \%$, Order Fullfillment Cycle Time $(O C F T)=$ 15 hari, Cost Of Good Sold $($ COGS $)=49.07 \%$, Cash To Cash Cycle Time $(C T C C T)=30$ hari. Metode ini $(S C O R)$ sangat tepat dan unggul untuk meningkatkan pelayanan kepuasan SCM.
\end{abstract}

Kata Kunci: pengukuran kinerja, manajemen rantai pasok, supply chain operation references (SCOR), value chain analysis (VCA)

\section{Abstract}

The main concept of SCM activity are to focus on the process of shipping and procuring goods. The previous studies have been analyzed the SCM activities by using the Value Chain Analyst (VCA) methodology. However, there are several problems in previous studies such as customer satisfaction analysis and an ending increase in the supply value chain. To solve the problems from the aforementioned, we propose to use Supply Chain Operations Reference (SCOR) to organize management and supply chain management performance levels. The purpose of this study was to describe the supply chain management performance and supply chain management performance levels in PT Nieve Aplikasi Mandiri, as measured using the supply chain operation reference (SCOR). The steps carried out in a research based on the SCOR method, namely, first weighting the importance of the SCOR indicator. Second, categorizing the level of SCM performance indicators. The results of these study indicates that the delivery and procurement by using the SCOR method in level 1 metric obtained Perfect Order Fullfillment $(P O F)=72.28 \%$, Order Fullfillment Cycle Time $($ OCFT $)=15$ days, Cost Of Good Sold $($ COGS $)=49.07 \%$, Cash To Cash Cycle Time $($ CTCCT $)=30$ days. This method (SCOR) is very precise and superior for improving SCM satisfaction services.

Keywords: performance measurement, supply chain management, supply chain operation references (SCOR), value chain analysis (VCA)

\section{Pendahuluan}

Supply Chain Management (SCM) merupakan sebuah kegiatan mulai dari koordinasi, penjadwalan dan pengendalian terhadap pengadaan, persediaan dan pengiriman produk ataupun jasa 
kepada pelanggan, SCM adalah kegiatan yang menggabungkan semua pihak yang bersangkutan dalam proses perubahan bahan baku menjadi sebuah produk. Pada SCM ada beberapa pihak yang ikut serta memberikan barang-barang jadi (produksi) ke customer pada waktu dan tempat yang tepat dengan cara yang efisien. Dengan berkembangnya teknologi yang semakin cepat, maka kebutuhan manusia menggunakan teknologi semakin besar. Peran teknologi saat ini sangat diperlukan untuk membantu beberapa perusahaan dalam meningkatkan kegiatan operasionalnya. Mulai dari kegiatan koordinasi, penjadwalan, pengendalian, pengadaan, persediaan dan pengiriman produk ataupun jasa kepada pelanggan. Sebuah teknologi informasi sangat diperlukan dalam sebuah perusahaan untuk menjalankan kegiatan operasionalnya sebagai sarana untuk mempermudah pencapaian kebutuhan dari pengadaan hingga pengiriman barang. Dengan adanya konsep dari teknologi informasi yang diterapkan pada SCM diharapkan aktivitas yang dilakukan dapat berjalan lebih terorganisir dan dapat diawasi pihak terkait sesuai dengan perjanjian layanan yang telah disepakati [1].

Untuk mengetahui performansi supply chain perusahaan, diperlukan suatu pengukuran menggunakan metode Supply Chain Operation Reference (SCOR). Metode SCOR adalah suatu model acuan dari operasi supply chain. SCOR mampu memetakan bagian-bagian supply chain dengan aktivitas suatu perusahaan yang dimana, harus mengatur dan mengawasi perhitungan terhadap pengiriman dan pengadaan barang dengan memperhitungkan modal dan keuntungan yang didapatkan [2]. SCOR memiliki fungsi untuk menyajikan kerangka proses bisnis, indikator kinerja, serta mendukung kolaborasi antarmitra, sehingga dapat menigkatkan efektivitas manajemen dan penyempurnaan rantai suplai. Dari studi kasus yang telah dilakukan sebelumnya, menggunakan metodologi Value Chain Analyst (VCA) terdapat beberapa permasalahan seperti analisis rantai pasokan dan diikuti oleh analisis kepuasan pelanggan yang diakhiri peningkatan rantai nilai pasokan. Analisis kualitatif menggambarkan sebuah rantai pasokan dengan kepuasan pelanggan, sedangkan analisis kuantitatif digunakan untuk mengetahui nilai tambah pada pembentukan rantai nilai [3]. Studi kasus sebelumnya menggunakan metode VCA dimana value yang didapat mencapai $30 \%-50 \%$ dari total produksi, yang artinya waste (segala sesuatu yang tidak memiliki nilai tambah) dapat mencapai 50\% menyebabkan target produksi tidak terpenuhi, sehingga perusahaan mulai menunjukkan tren positif, akan tetapi angka produksi menunjukkan tren negatif di tahun berikutnya [4]. Permasalahan yang ada dalam penelitian sebelumnya mirip dengan penelitian yang dilakukan pada perusahaan (PT Nieve Aplikasi Mandiri). Untuk mengatasi permasalahan yang ada, usulan yang diberikan menggunakan metode SCOR, dimana pembuatan sistem pengukuran kinerja yang berbasis kepada SCM bertujuan untuk mengendalikan dan melakukan evaluasi terhadap kinerja secara berkesinambungan untuk menciptakan keunggulan dalam bersaing [5]. Langkah-langkah yang dilakukan dalam penelitian yang berbasis pada metode SCOR yakni, pertama melakukan pembobotan tingkat pada kepentingan indikator SCOR, kedua mengkategorikan tingkatan indikator kinerja SCM, manfaat dari metode SCOR ialah mampu mengetahui seberapa besar kinerja perusahaan sampai saat ini, dibandingkan dengan pesaingnya. Selain itu, perusahaan juga diharapkan mampu mengetahui letak kelemahan dalam bersaing di perindustrian [6].

\section{Tinjauan Literatur}

Beberapa hasil penelitian sebelumnya yang berkaitan dengan supply chain management, dan supply chain operation reference (SCOR) digunakan untuk menunjang penelitian yang dilakukan. Istilah SCM di dalam dunia bisnis didefinisikan sebagai pembuat keputusan lebih baik mengenai kapan dan berapa banyak dalam proses melakukan pembelian, produksi, ataupun pengiriman [7]. Untuk kegitan bisnis berbasis jasa pada proses SCM adalah bagaimana konsumen merasa puas terhadap hasil kinerja suatu perusahaan jasa atau juga dapat diartikan kegiatan yang menggabungkan semua pihak yang bersangkutan dalam proses perubahan bahan baku menjadi sebuah produk [8].

Konsep supply chain management adalah sistem yang memungkinkan perpindahan barang dari produsen agar hal-hal seperti keterlambatan penyampaian, salah barang, dan sebagainya bisa dikurangi atau tidak terjadi [9]. Perusahaan pada umumnya mengadopsi konsep supply chain dalam melihat seluruh rangkaian kegiatan dari produksi hingga pengiriman barang seperti yang dijelaskan pada Gambar 1 berikut. 


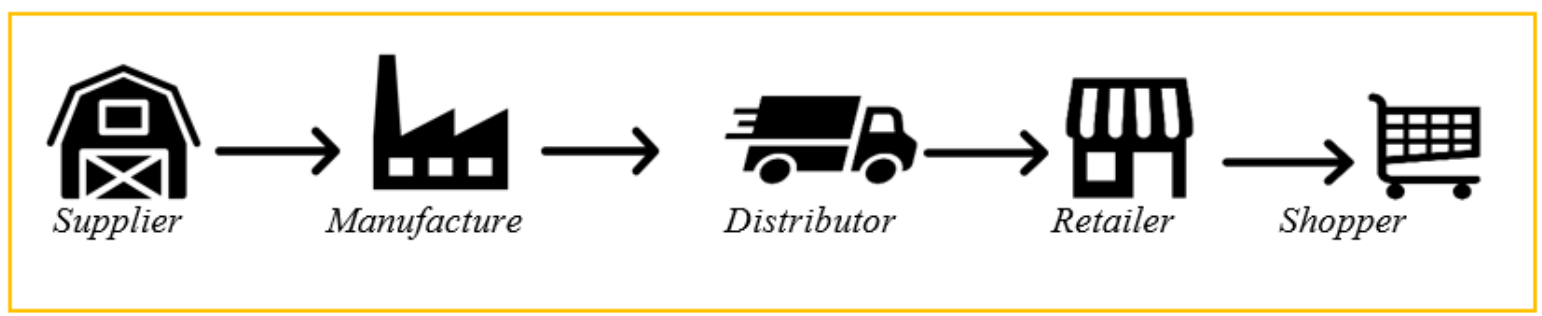

Gambar 1. Konsep Supply Chain Management

Gambar 1 menjelaskan keseluruhan kegiatan yang berada mulai dari proses supplier saat barang masih berupa bahan baku, lalu diolah menjadi barang jadi, hinga pendistribusian barang sampai ke retailer, hingga proses akhir yakni barang siap pakai sampai di tangan customer. Tujuan utama dari konsep manajemen rantai pasokan adalah mengkordinasi kegiatan rantai pasokan untuk memaksimalkan keunggulan kompetitif [10].

\subsection{Supply Chain Operation Reference (SCOR)}

SCOR Model adalah sebuah metode yang dikembangkan oleh Supply Chain Council atau Dewan Rantai Suplai, SCOR menyajikan mengenai kerangka proses bisnis, indikator kinerja, serta teknologi untuk mendukung kolaborasi antarmitra rantai suplai [11]. Penggunaan metode ini demi memberikan sebuah alternative ataupun solusi terhadap permasalahan yang terjadi dengan menggunakan tolak ukur yang digunakan untuk mengukur kinerja operasional dari perusahaan dan menetapkan targettarget yang akan dicapai perusahaan. SCOR adalah sebuah bahasa rantai suplai, yang dapat digunakan dalam berbagai konteks untuk merancang, mendeskripsikan, dan mengkonfigurasi ulang berbagai jenis aktivitas komersial bisnis. Penerapan metode SCOR dalam batas-batas tertentu cukup fleksibel dan dapat disesuaikan untuk meningkatkan produktivitas demi memenuhi kebutuhan konsumen. SCOR merupakan model referensi proses yang menggabungkan konsep-konsep dalam rekayasa ulang proses bisnis, benchmarking, dan pengukuran proses. Dalam pencapaian tujuan rantai suplai akan dilakukan analisa melalui indikator dalam atribut kinerja yaitu reliability, responsiveness, supply chain costs, dan asset management. Keuntungan menggunakan metode SCOR yakni, 1) dapat memperlihatkan hubungan antara tujuan umum perusahaan (taktik dan strategi) dengan operasi SCM secara keseluruhan, 2) SCOR juga dapat melakukan identifikasi, evaluasi, dan memonitoring performa kinerja SCM [12].

\subsection{Metrik Pengukuran Kinerja SCOR}

Pada penerapan metode SCOR pengukuran dilakukan untuk dapat mengidentifikasi indikator kinerja rantai pasok dengan menunjukan proses rantai pasok perusahaan. Pengukuran kinerja dilakukan dengan menilai parameter-parameter kinerja, seperti manajemen aset, profitabilitas, tingkat pelayanan, dan waktu pengiriman sehingga dapat dijadikan evaluasi dalam meningkatkan kinerja. Tahap awal yang dilakukan yaitu pengumpulan data, yang terdiri dari klasifikasi pemetaan rantai pasok yang didapatkan dengan cara observasi dan wawancara dengan pihak yang terkait dalam proses rantai pasok, kemudian data diklasifikasikan berdasarkan 4 proses inti yaitu reliability, responsiveness, cost, dan asset [5], [13].

\subsection{Value Chain Analysis}

Value Chain Analysis adalah proses di mana sebuah perusahaan mengidentifikasi kegiatan utama dan bantuan yang menambah nilai produk, kemudian menganalisisnya untuk mengurangi biaya atau meningkatkan diferensiasi. Value Chain Analysis merupakan strategi yang digunakan untuk mengalisis kegiatan internal perusahaan. Dengan kata lain, dengan melihat ke dalam kegiatan internal, analisis itu mengungkap di mana keunggulan kompetitif suatu perusahaan atau kekurangannya. Perusahaan yang bersaing melalui keunggulan diferensiasi akan mencoba untuk melakukan kegiatan yang lebih baik dari yang akan dilakukan pesaing. Ketika sebuah perusahaan mampu memproduksi 
barang dengan biaya yang lebih rendah dari harga pasar atau untuk memberikan produk-produk unggulan, untuk memperoleh keuntungan [3].

\subsection{Metrik Pengukuran Value Chain Analysis}

Pada metode value chain analysis tahapan yang dilakukan yakni kegiatan perusahaan dibagi menjadi dua bagian besar, yaitu kegiatan utama (primary activities) dan kegiatan pendukung (support activities). Kegiatan utama dibagi menjadi lima, yaitu logistik masuk (inbound logistics), manajemen operasi (operations), logistik keluar (outbound logistics), pemasaran dan penjualan (marketing and sales), serta pelayanan (service). Kegiatan pendukung dibagi empat, yaitu infrastruktur perusahaan (firm infrastructure), manajemen SDM (human resource management), teknologi (technology), serta pengadaan (procurement) [3].

\section{Metode penelitian}

Pengembangan aplikasi Supply Chain Management dilakukan PT Nieve Aplikasi Mandiri, menggunakan metode perhitungan SCOR.

\subsection{Pengukuran SCOR}

Metode Pengelolaan dan analisis data yakni untuk mempermudah peneliti dalam mengelola data, dan membuat target-target yang dibutuhkan dalam penelitian [13]. Baik data primer maupun data sekunder yang berhasil dikumpulkan maka data akan dibuat menjadi data kuantitatif dalam berbentuk angka yang siap dianalisis. Teknik analisis yang digunakan untuk mengelolah dan menganalisis data yang sudah dikumpulkan terdiri atas tahapan pengelolaan data pada Tabel 2.

Tabel 2. Dimensi, Indikator, \& Ukuran

\begin{tabular}{llll}
\hline No & Dimensi & Indikator & Ukuran \\
\hline 1 & Reliability & Perfect Order Fullfillment & $\%$ \\
2 & Responsiveness & Order Fullfillment Cycle Time & Hari \\
3 & Cost & Supply Chain Management Cost & Rp \\
& & Cost Of Good Sold & $\%$ \\
4 & Asset & Cash To Cash Cycle Time & Hari \\
\hline
\end{tabular}

Dengan demikian, benchmark kinerja perusahaan yang telah ada, diukur dengan model SCOR versi 11.0. Jika hasilnya sesuai dengan standar benchmark dari model SCOR 11.0, maka dikatakan perusahaan tersebut baik dalam menerapkan sistem rantai pasok. Jika belum, maka perusahaan perlu meninjau kembali strategi SCM yang telah ditetapkan.

Dari serangkaian pengukuran dengan model SCOR 11.0. Terdapat lima attribute yang digunakan pada penilaian performa dari supply chain dengan menggunakan metode SCOR model version 11.0. dalam satu attribute, terdapat beberapa metrik yang dapat dipakai sebagai metrik pengukuran kinerja supply chain [14]. Berikut lima attribute SCOR model version 11.0 pada Tabel 3.

\section{Tabel 3. Performance Attributes}

\begin{tabular}{lll}
\hline No & Performance & Definisi \\
\hline 1 & Supply Chain Reliability & Kemampuan rantai pasok dalam \\
& & mengirim produk dengan tepat, \\
& pada tempat yang tepat, pada \\
& & waktu yang tepat, dengan jumlah \\
& & yang tepat dan terdokumentasi \\
& & dengan baik. \\
\hline 2 & Supply Chain Responsiveness & Kecepatan rantai pasok dalam \\
& & menyediakan produk ke \\
& & konsumen. \\
& &
\end{tabular}




\begin{tabular}{llll}
\hline 3 & Supply Chain Agility & $\begin{array}{l}\text { Kemampuan rantai pasok dalam } \\
\text { merspon perubahan pasar dalam } \\
\text { upaya memenangkan persiangan } \\
\text { pasar. }\end{array}$ \\
\hline 4 & Supply Chain Cost & $\begin{array}{l}\text { Biaya-biaya yang berhubungan } \\
\text { dengan pengoprasian rantai pasok. }\end{array}$ \\
\hline 5 & Supply Chain Asset Management & $\begin{array}{l}\text { Nilai keefektifan dari suatu } \\
\text { organisasi untuk mengatur } \\
\text { assetnya untuk mendukung } \\
\text { kepuasan permintaan. Ini } \\
\text { termasuk fixed capital dan } \\
\text { working capital. }\end{array}$ \\
& &
\end{tabular}

Sumber : (Supply Chain Operation References (SCOR) Overview of Model Version 11.0)

Berdasarkan struktur metric kinerja SCOR model version 11.0 dibagi dalam 3 aspek utama sistem metrik yaitu :

1. Costumer facing, yaitu untuk mengukur suatu atribut kinerja Supply Chain Delivey Reliability, Responsiveness dan Agility terhadap pelanggan dan supplier.

2. Internal facing, yaitu untuk mengukur sebuah biaya rantai pasok (Supply Chain Cost) dan efisiensi manajemen asset.

3. Shareholder facing, yaitu untuk mengukur profitability, efficiency of return dan share performance.

\section{$4 \quad$ Hasil dan pembahasan}

Pada bagian ini akan membahas mengenai hasil penelitian yang telah dilakukan sebagai berikut:

\subsection{Analisis Proses Bisnis}

Pada penelitian ini ditemukan sebuah masalah pada sistem yang sedang berjalan yaitu tidak adanya penilaian performance supply chain yang dilakukan oleh perusahaan untuk menentukan keberhasilan supply chain, hal ini didapatkan setelah melakukan wawancara kepada karyawan di PT Nieve Aplikasi Mandiri sehingga peneliti mengusulkan proses bisnis seperti Gambar 4.

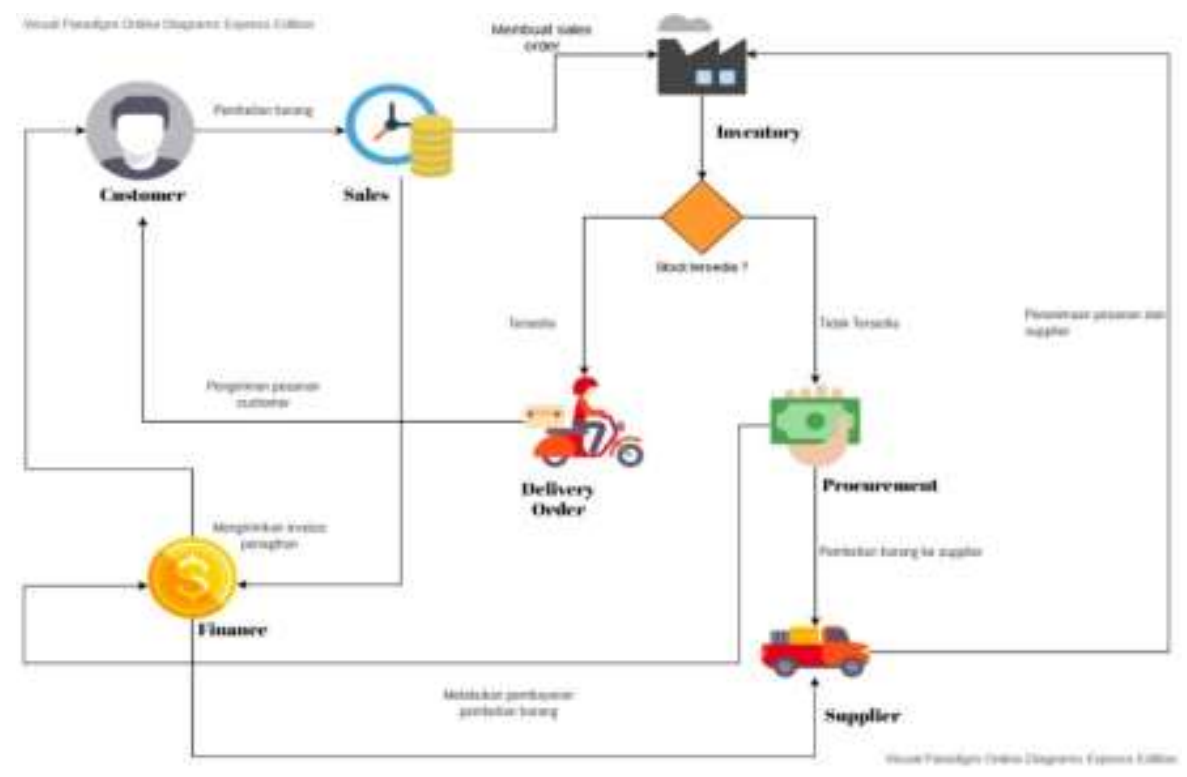

Gambar 4. Analisis Proses Bisnis 
Pada tahapan ini menjelaskan proses bisnis mengenai sistem berbasis framework odoo modul SCM yang dimana sales melakukan permintaan barang sesuai kebutuhan customer di sistem, jika barang tersedia di bagian Gudang maka bagian Gudang akan melakukan pengiriman barang ke customer. Jika barang tidak tersedia di Gudang maka bagian procurement akan memproses pembelian barang ke supplier lalu bagian finance akan melakukan tugasnya dalam proses pembayaran ataupun penagihan ke customer keunggulan pada sistem ini adalah mencatat mulai dari proses permintaan barang hingga barang diterima oleh customer. Pada sistem ini maka akan terlihat model SCOR pada bagian sales, finance, dan inventory dimana akan ditampilkan sebuah dashboard untuk mengetahui proses yang dilakukan oleh tiap bagian yang terlibat.

\subsection{Metrik SCOR \& VCA}

Dari data yang didapatkan maka diberikan analisis data maka perbandingan metode yang digunakan sebagai berikut:

\subsubsection{Metrik SCOR}

Pada Metode SCOR pengelolaan dan analisis data dilakukan agar mempermudah dalam mengelola data, dan membuat target-target yang dibutuhkan dalam penelitian. Baik data primer maupun data sekunder yang berhasil dikumpulkan, maka data tersebut akan dibuat dalam berbentuk angka, berikut metrik yang digunakan pada perhitungan metode SCOR:

A. Perfect Order Fulfilment(POF)

$$
P O F=\frac{\text { Jumlah pesanan sempurna }}{\text { Jumlah total pesanan }} \times 100 \%
$$

B. Order Fulfilment Cycle-Time (OFCT)

$$
O C F T=\frac{\text { Jumlah waktu pengiriman pesanan }}{\text { Jumlah total pesanan yang dikirim }}
$$

D. Supply Chain Management $\operatorname{Cost}(\mathrm{SCMC})$

$$
\text { SCMC }=\text { Sales }- \text { Profit }- \text { Cost to Serve }
$$

E. Cost of Good Sold(COGS)

$$
\text { COGS }=\text { Plan }+ \text { Source }- \text { Siklus kas }
$$

F. Cash-to-Cash Cycle Time(CTCCT)

$$
\text { CTCCT }=\text { Jadwal Pengiriman }+ \text { Jumlah Pemasukan }- \text { Jumlah Pengeluaran }
$$

Teknik analisis data yang digunakan untuk mengelolah dan menganalisis data yang sudah dikumpulkan terdiri atas 4 tahapan dengan hasil sebagai berikut:

\begin{tabular}{|c|c|c|c|}
\hline Bulan & Total Pesanan & Pesanan Bermasalah & POF \\
\hline Januari & 210 & 55 & $73.89 \%$ \\
\hline Februari & 749 & 105 & $59.27 \%$ \\
\hline Maret & 235 & 75 & $68.08 \%$ \\
\hline April & 190 & 23 & $87.89 \%$ \\
\hline Total & & & $72.87 \%$ \\
\hline
\end{tabular}

\subsubsection{Perhitungan Kerja Metrik SCOR}

Pada Tabel 2, 3, 4 dan 5 merupakan hasil analisis yang didapatkan dari data pengiriman dan keuangan.

Tabel 4. Hasil Perhitungan POF

Sumber data bagian pembelian dan pengiriman barang 
Rata-rata POF PT Nieve Aplikasi Mandiri ialah:

$$
P O F=\frac{73.89 \%+59.27 \%+68.08 \%+87.89 \%}{4} \times 100 \%=72.28 \%
$$

Tabel 5. Hasil Perhitungan OCFT

\begin{tabular}{cccc}
\hline & Bulan & Total Pesanan & Total OCFT (Hari) \\
\hline & Januari & 210 & 8 Hari \\
& Februari & 749 & 29 Hari \\
& Maret & 235 & 15 Hari \\
& April & 190 & 7 Hari \\
\hline Total & & & $14 \sim 15$ Hari
\end{tabular}

Sumber data bagian pengiriman barang

Rata-rata OCFT PT Nieve Aplikasi Mandiri ialah:

$$
\text { OCFT }=\frac{8 \text { hari }+29 \text { hari }+15 \text { hari }+7 \text { hari }}{4}=14 \text { hari } \sim 15 \text { hari }
$$

Tabel 6. Hasil Perhitungan COGS

\begin{tabular}{crrrr}
\hline Bulan & \multicolumn{1}{c}{ Sales (Rp) } & \multicolumn{1}{c}{ Profit (Rp) } & Cost To Serve (Rp) & COGS (\%) \\
\hline \multirow{2}{*}{ Januari } & 2.685 .338 .000 & 715.022 .000 & 99.837 .500 & $17 \%$ \\
Februari & 5.004 .901 .500 & 3.807 .229 .500 & 567.778 .750 & $29 \%$ \\
Maret & 3.355 .741 .000 & 1.304 .245 .000 & 100.807 .500 & $17 \%$ \\
April & 475.837 .273 & 284.677 .273 & 64.230 .625 & $19 \%$ \\
\hline Total & & & & $49.07 \%$ \\
\hline
\end{tabular}

Sumber data bagian penjualan $\&$ pendapatan

Rata-rata COGS PT Nieve Aplikasi Mandiri ialah:

$$
\mathrm{COGS}=\frac{17 \%+29 \%+17 \%+19 \%}{4}=49.07 \%
$$

Tabel 7. Hasil Perhitungan CTTCT

\section{Metrik $\quad$ Deliver (Hari) $\quad$ Account Payable (Hari) $\quad$ Account Receiveable (Hari)}

$\begin{array}{llll}\text { CTTCT (Hari) } & \text { 30 Hari } & 7 \text { Hari }\end{array}$

Sumber data bagian penjualan \& pengiriman

Maka data yang diperolah oleh CTCCT pada PT Nieve Aplikasi Mandiri yakni:

$$
\text { CTCCT }=30 \text { hari }+7 \text { hari }-7 \text { hari }=30 \text { Hari }
$$

\subsubsection{Metrik VCA}

Value Chain Analyst (VCA) adalah sebuah teknik yang menerapkan secara luas mengenai bidang manajemen operasi, rekayasa proses, dan manajemen rantai pasokan, untuk analisis dan peningkatan selanjutnya dari pemanfaatan sumber daya dan aliran produk dalam proses manufaktur.

Berikut metrik yang digunakan pada metode VCA yakni: 
A. Kepercayaan \& Komitmen

B. Lead time supply chain

$$
\text { Skala Interval }=\frac{\text { Nilai Tertinggi }- \text { Nilai Terendah }}{\text { Skala yang mungkin akan muncul }}
$$

$$
\text { LTsc }=\text { LT waiting }+ \text { LT proses }+ \text { LT waiting proses }
$$

C. Benefit / Cost Ratio (B / CR)

$$
\frac{\mathrm{B}}{\mathrm{C}} \text { Ratio }=\frac{\text { Pendapatan dari produksi yang hilang }}{\text { Penambahan Produksi }}
$$

Pada VCA ini memiliki perhitungan untuk memudahkan peneliti dalam mengelola data ataupun aktifitas yang dilakukan perusahaan yang menghasilkan sebuah nilai, berikut ilustrasi analisis rantai nilai yang dilakukan dengan tahapan sebagai berikut:

\subsubsection{Perhitungan Kerja Metrik VCA}

1. Kepercayaan \& Komitmen

Jawaban yang diberikan oleh responden dicatat dengan kuisioner, kemudian diberikan nilai dengan kategori sebagai berikut:

Tabel 8. Kategori Kuesioner

\begin{tabular}{ccc}
\hline No & Kategori & Skor \\
\hline 1 & Sangat Baik & 5 \\
2 & Baik & 4 \\
3 & Cukup Baik & 3 \\
4 & Kurang Baik & 2 \\
5 & Tidak Baik & 1 \\
\hline
\end{tabular}
Tabel 6

Pada Tabel 7 merupakan penjelasan mengenai skala penilaian terhadap kategori kuesioner pada

Tabel 9. Skala Kategori Kuesioner

\begin{tabular}{ccc}
\hline No & Kategori & Skala \\
\hline 1 & Sangat Baik & $1303-1550$ \\
2 & Baik & $1055-1302$ \\
3 & Cukup Baik & $807-1054$ \\
4 & Kurang Baik & $559-806$ \\
5 & Tidak Baik & $311-559$ \\
\hline
\end{tabular}

Pada Tabel 10 merupakan hasil perhitungan kuesioner terhadap jawaban yang diberikan oleh responden yang telah dicatat.

Tabel 10. Hasil Perhitungan Kuesioner

\begin{tabular}{ccccccc}
\hline Bulan & Responden & $\mathbf{5}$ & $\mathbf{4}$ & $\mathbf{3}$ & $\mathbf{2}$ & $\mathbf{1}$ \\
\hline Januari & 16 & 1 & 4 & 8 & 3 & 0 \\
Februari & 15 & 1 & 6 & 8 & 0 & 0 \\
Maret & 16 & 1 & 5 & 7 & 3 & 0 \\
April & 15 & 1 & 4 & 8 & 2 & 0 \\
Jumlah & 62 & 4 & 19 & 31 & 18 & 0 \\
\hline Total & 1045 & 100 & 380 & 465 & 100 & 0 \\
\hline & & & & & http://sistemasi.ftik.unisiac.id
\end{tabular}


Maka data yang diperoleh dari perhitungan kuesioner PT Nieve Aplikasi Mandiri yang dilakukan sebagai berikut :

Skor tertinggi: $5 \times 62 \times 5=1550$

Skor terendah: $5 \times 62 \times 1=310$

Skala Interval: $(1550-310) \div 5=248$

Dari perhitungan yang dilakukan maka didapatkan Total skor adalah 1045. Berdasarkan Tabel 7 , maka total skor tersebut termasuk kategori cukup baik.

2. Lead Time Supply Chain

Tabel 11. Hasil Perhitungan Rantai Pasok

\begin{tabular}{ccccc}
\hline Bulan & Data Received at Log & Qty & Ship out (Hari) & Durasi (Jam) \\
\hline Januari & 15 & 113 & 30 & 60 \\
Februari & 16 & 23 & 15 & 30 \\
Maret & 28 & 10 & 29 & 58 \\
April & 13 & 77 & 14 & 28 \\
\hline Total & 72 & 223 & 88 & 176 \\
\hline
\end{tabular}

Rata-rata perhitungan leadtime supply chain PT Nieve Aplkasi Mandiri didapatkan pengertian sebagai berikut :

Lead Time waiting = Ship Out - Data Received

Lead Time proses $=$ Qty $\div$ Lead Time waiting

Lead Time waiting proses $=$ Durasi $\div$ Qty

Dengan data yang didapatkan dari Lead Time Supply Chain PT Nieve Aplikasi Mandiri yakni:

$$
\text { LTsc }=16+13.937+0.790=30.727
$$

3. Benefit Cost Ratio $\left(\frac{\mathrm{B}}{\mathrm{C}}\right.$ ratio $)$

Tabel 12. Perhitungan Ukuran Perbandingan Antara Pendapatan

\begin{tabular}{ccccc}
\hline No & Kategori & Additional Production (Rp) & $\begin{array}{c}\text { Income From Lost } \\
\text { Production (Rp) }\end{array}$ & Duration (Jam) \\
\hline 1 & Januari & 2.685 .338 .000 & 715.022 .000 & 39 \\
2 & Februari & 5.004 .901 .500 & 3.807 .229 .500 & 34 \\
3 & Maret & 3.355 .741 .000 & 1.304 .245 .000 & 21 \\
4 & April & 475.837 .273 & 284.677 .273 & 14 \\
\hline Total & & 11.521 .817 .773 & 6.111 .173 .773 & 108 \\
\hline
\end{tabular}

Rata - Rata dari perhitungan $\frac{\mathrm{B}}{\mathrm{C}}$ ratio PT Nieve Aplikasi Mandiri ialah:

$\frac{\mathrm{B}}{\mathrm{C}}$ ratio $=$ Pendapatan dari produksi yang hilang $/$ Penambahan produksi

$$
\frac{\mathrm{B}}{\mathrm{C}} \text { ratio }=\frac{6.111 .173 .773}{11.521 .817 .773}=0.530
$$

Angka $\frac{B}{C}$ ratio kurang dari 1 menandakan bahwa cost yang dikeluarkan jauh lebih besar dibandingkan dengan pendapatan yang diterima oleh perusahaan, disebabkan oleh naiknya harga barang yang dibeli ke supplier sehingga cost yang dibutuhkan di awal lebih besar. 


\subsection{Implementasi Sistem SCM}

1. Halaman Sales Order

Pada menu ini berisi data sales order yang telah diinput. Pada halaman ini berisikan tentang no sales order, tanggal permintaan, customer, sales person, harga barang, dan status order. Dapat dilihat pada Gambar 6.

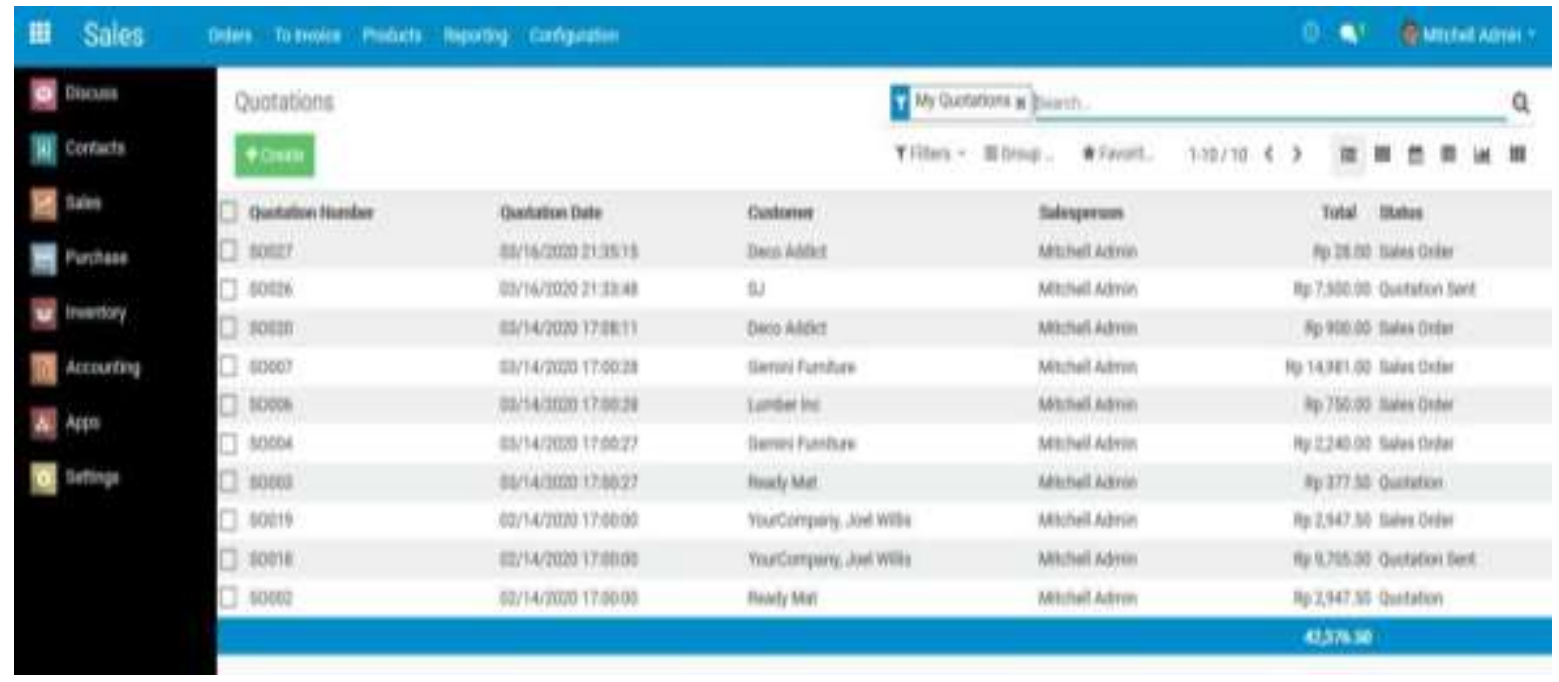

Gambar 6. Halaman Sales Order sistem SCM

Pada menu sales order sistem SCM setelah memilih menu order lalu memilih create maka sistem akan menampilkan form pengajuan barang yang berisikan nama customer, metode pembayaran, product yang dibeli, jumlah, dan total harga yang akan kita input pada sistem. Pada bagian ini maka diterapkan model SCOR pada perhitungan POF dimana dashboard berisikan jumlah total pesanan dan pesanan yang telah dikirimkan oleh bagian Gudang.

\section{Halaman Purchase Order}

Berisi Tampilan pembelian barang yang dilakukan oleh team procurement (pembelian), yang dimana berisikan data nomor purchase order (Reference), tanggal pembelian, nama supplier, Tanggal pengiriman barang, user yang melakukan input, sumber pembelian, data pajak pembelian barang, total harga, dan status barang yang dijelaskan pada Gambar 7.

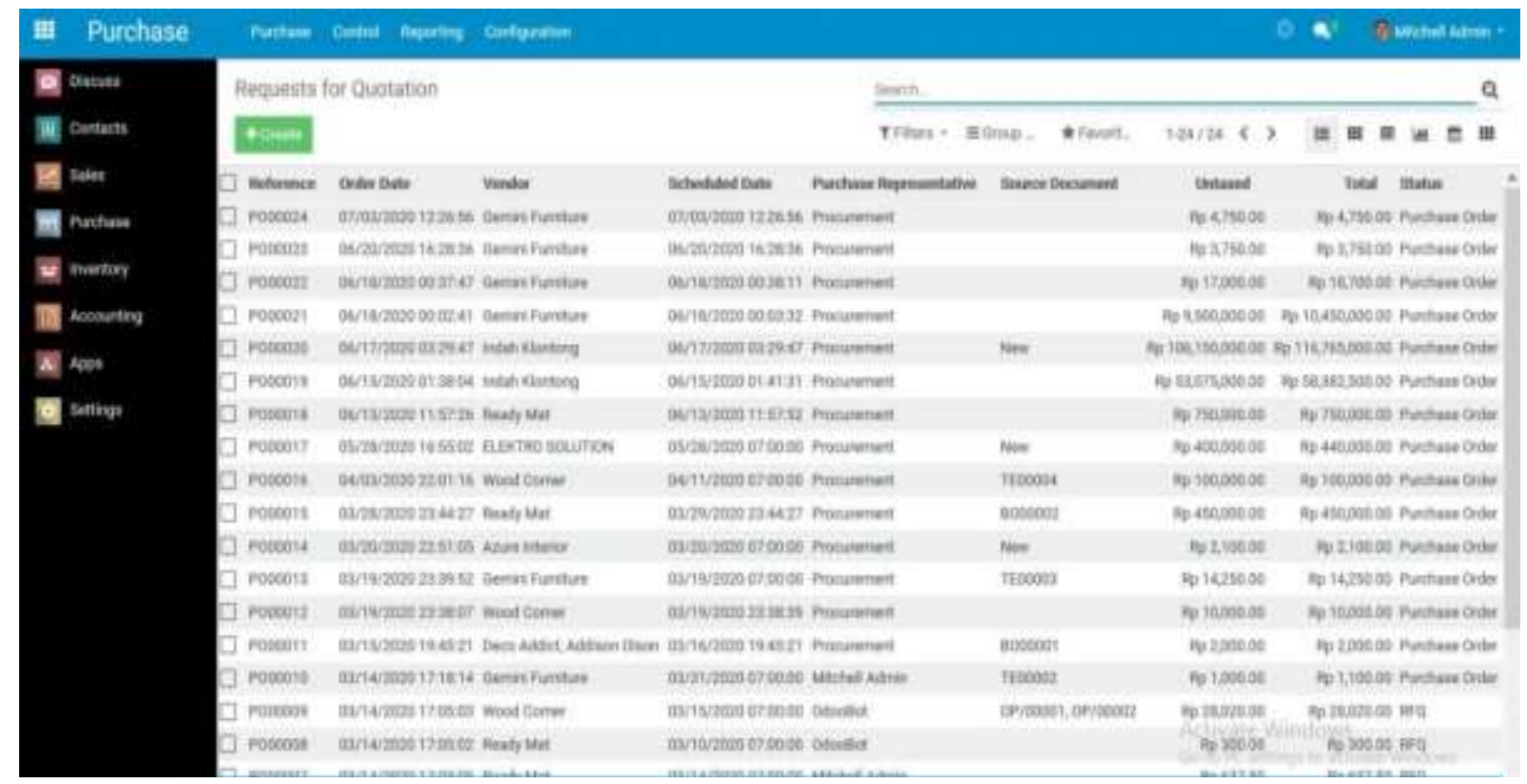

Gambar 7. Halaman Purchase Order 
Pada menu purchase order maka ada 2 menu yang bisa kita pilih yaitu request for quotation untuk melakukan penawaran harga dan purchase order jika sales sudah melakukan input permintaan barang maka data akan muncul pada purchase order setelah itu data yang masuk akan diproses oleh procurement untuk pembelian barang ke supplier. Pada halaman purchase order data diperoleh dari permintaan yang dilakukan oleh sales sehingga metrik yang digunakan dalam model SCOR menggunakan metrik COGS dimana berisikan data mengenai pembelian, biaya pengiriman, dan keutungan yang diperoleh.

3. Halaman Overview Inventory

Pada menu ini berisikan tentang data penerimaan dan pengiriman barang yang dilkakan oleh bagian Gudang dimana data berisikan menu Receipt dan Delivery Order Gambar 8.

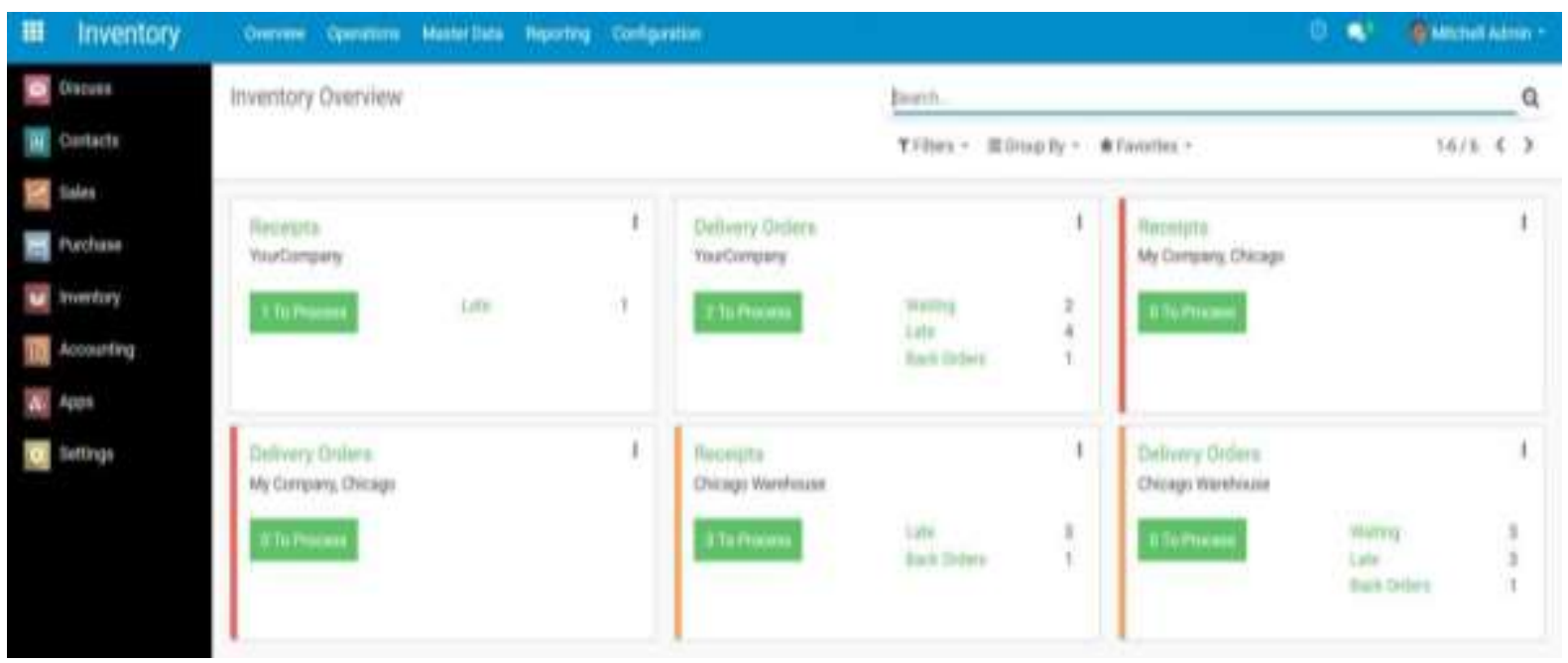

Gambar 8. Halaman Overview Inventory

Pada menu ini menampilkan data dashboard mengenai penerimaan dan pengiriman barang yang ada pada perusahaan. Menu yang ada pada sistem SCM bagian inventory diterapkan menggunakan metode perhitungan OCFT (Order Fulfilment Cycle-Time) dimana menggunakan waktu yang dibutuhkan untuk pengiriman dan jumlah barang yang dikirimkan.

\section{Halaman Receipt Inventory}

Pada menu ini menjelaskan data barang yang di terima oleh bagian Gudang, yang dimana data terhubung dengan data pembelian barang yang berada pada menu Purchase Order. Data berisikan nomor reference penerimaan barang, nama supplier, tanggal penerimaan, sumber dokumen pembelian, barang yang diterima jumlah belum sesuai, dan status penerimaan. Dijelaskan pada Gambar 9. 


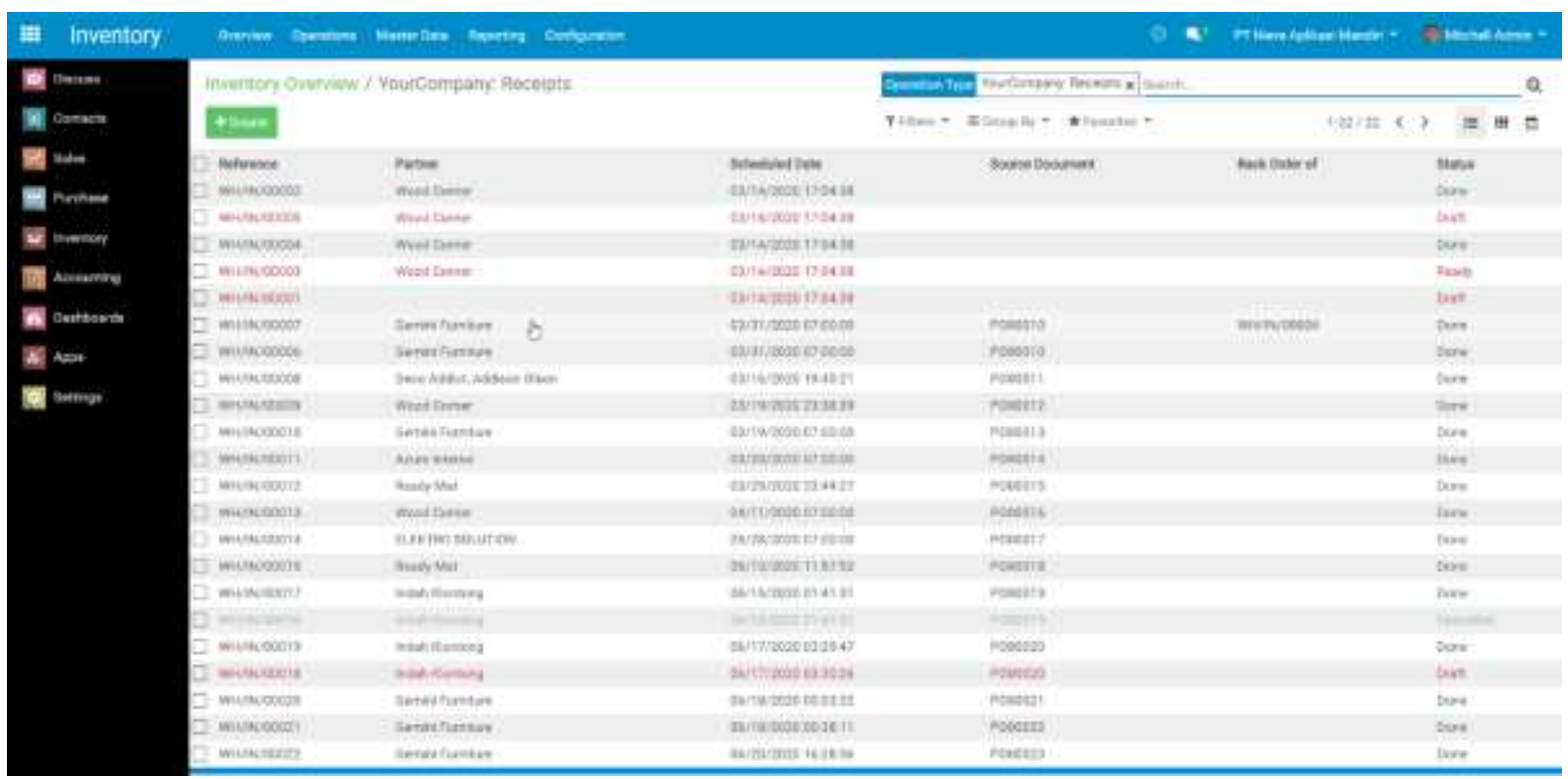

\section{Gambar 9. Tampilan Receipt Inventory}

Pada menu ini warehouse yang melakukan validasi penerimaan barang yang sudah dikirimkan oleh supplier sistem akan mengupdate stock barang yang dimiliki oleh perusahaan.

\section{Halaman Delivery Order}

Pada menu ini menampilkan pengiriman barang yang dilakukan bagian Gudang ke customer, menu ini berisikan data nomor reference pengeluaran barang, nama customer, tanggal pengiriman, sumber dokumen permintaan, barang yang belum sesuai penerimaan, dan status pengiriman. Dijelaskan pada Gambar 10.

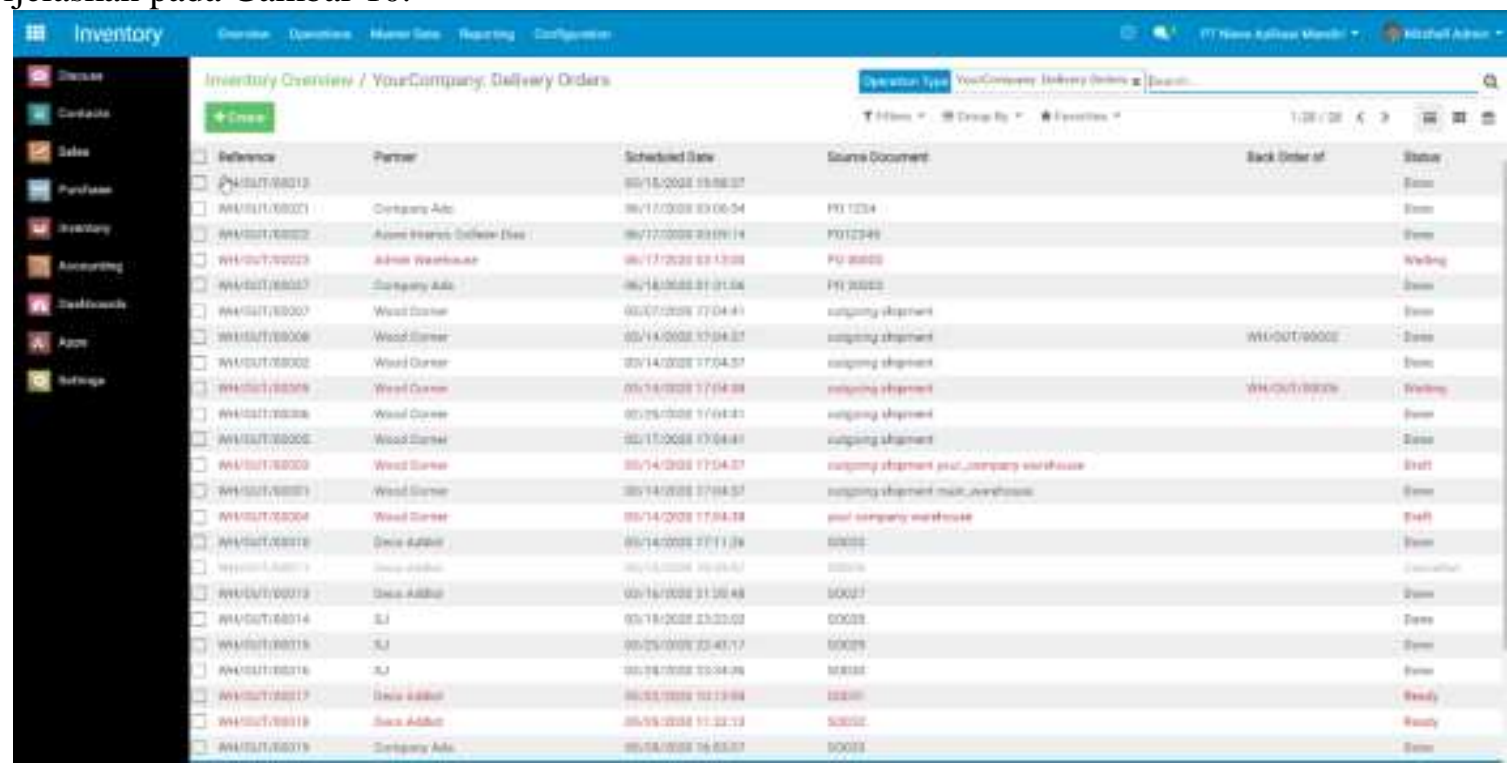

\section{Gambar 10. Halaman Delivery Order (inventory)}

Pada menu ini setelah memilih menu delivery order maka team warehouse akan memproses pengiriman barang ke customer yang telah diajukan oleh team sales, sistem akan mengupdate barang yang dikeluarkan yang dijual pada customer.

6. Halaman Overview Accounting

Pada menu ini menjelaskan tentang pembayaran atau penagihan untuk pembelian barang ataupun pembayaran jasa. Dijelaskan pada Gambar 11. 




Gambar 11. Halaman Overview Accounting

Pada menu ini menampilkan tentang arus pemasukan dan pengeluaran uang perusahaan menggunakan grafik dan secara mendetail. Pada menu accounting diterapkan metode perhitungan SCOR yakni COGS (Cost of Good Sold) dimana pencatatan dilakukan mulai dari modal yang dikeluarkan, hingga pendapatan yang diperoleh perusahaan.

7. Halaman Menu Invoices Accounting

Pada menu ini berisikan mengenai data penagihan kepada customer yang dilakukan oleh finance, data berisikan nama customer, tanggal penagihan, nomor invoice, nama sales, tanggal pembayaran akhir, data barang kena pajak, total penagihan, dan status penagihan. Dijelaskan pada gambar 12 .

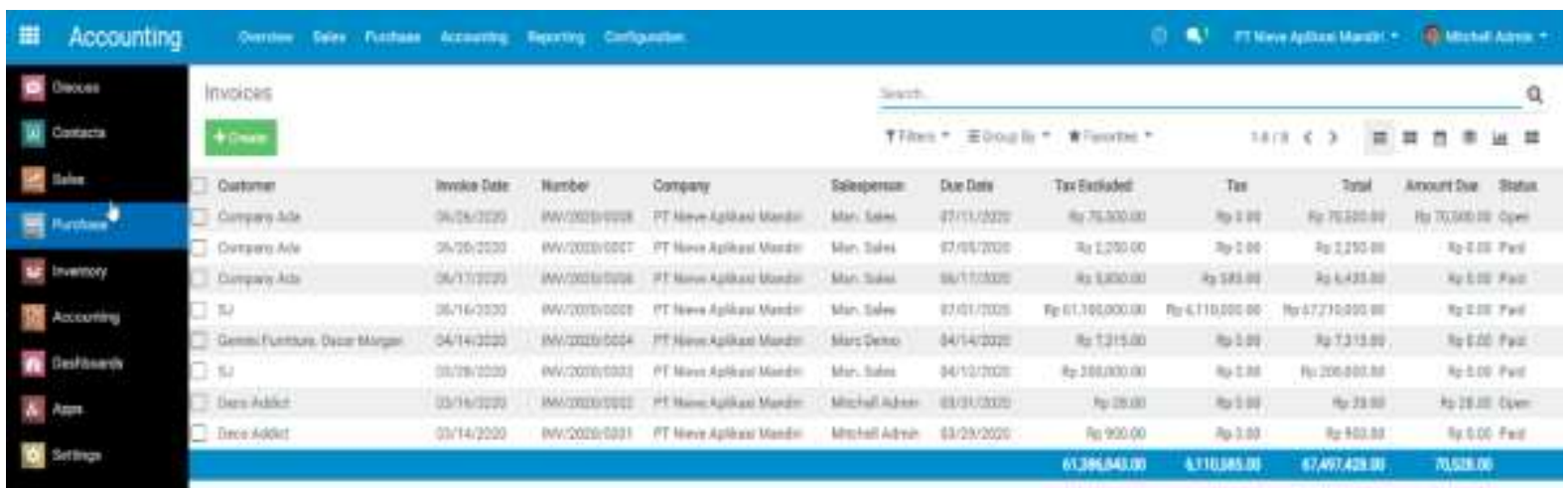

Gambar 12. Halaman Menu Invoices Accounting

Pada menu ini setelah finance memilih menu sales lalu memlihi submenu invoices, finance akan melakukan penagihan kepada customer sesuai jangka waktu pembayaran yang telah ditentukan, finance akan mengirimkan invoices setelah barang telah diterima oleh customer.

\section{Halaman Menu Vendor Bills Accounting}

Pada menu ini berisikan mengenai data pembayaran pembelian barang yang telah diterima dan di validasi penerimaan oleh team procurement untuk dilakukan pembayaran ke supplier, data berisikan nama supplier, tanggal pembayaran, nomor billing, nama perusahaan, pajak pembelian, total, dan status pembayaran. Dijelaskan pada Gambar 13. 


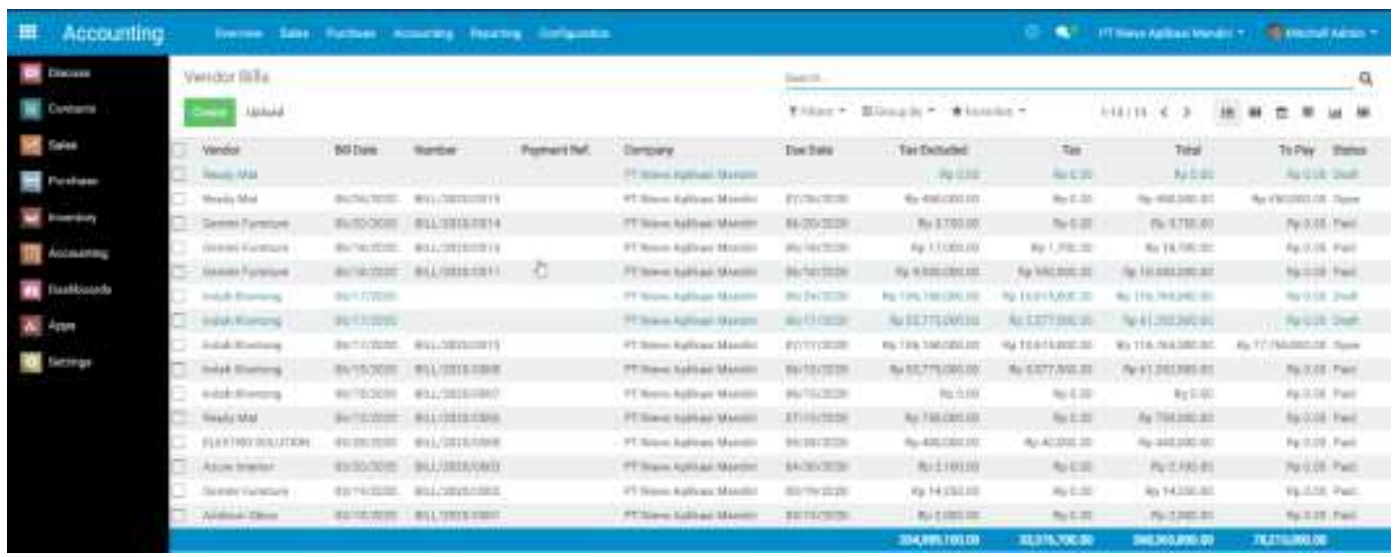

Gambar 13. Halaman Vendor Bills Accounting

Pada menu ini setelah barang yang diterima oleh warehouse, maka procurement akan melakukan register payment pada sistem, sistem akan menampilkan data pada menu dashboard, kemudian team finance memilih menu procurement di sistem lalu memilih submenu bills memilih data pembayaran barang yang akan dibayarkan ke supplier.

\section{Halaman Dashboard SCM Metrik SCOR}

Pada menu ini berisikan keseluruhan data yang ada pada sistem SCM dimana data tersebut diambil dari grafik yang ada pada setiap modul yang digunakan pada sistem SCM. Dijelaskan pada Gambar 14.

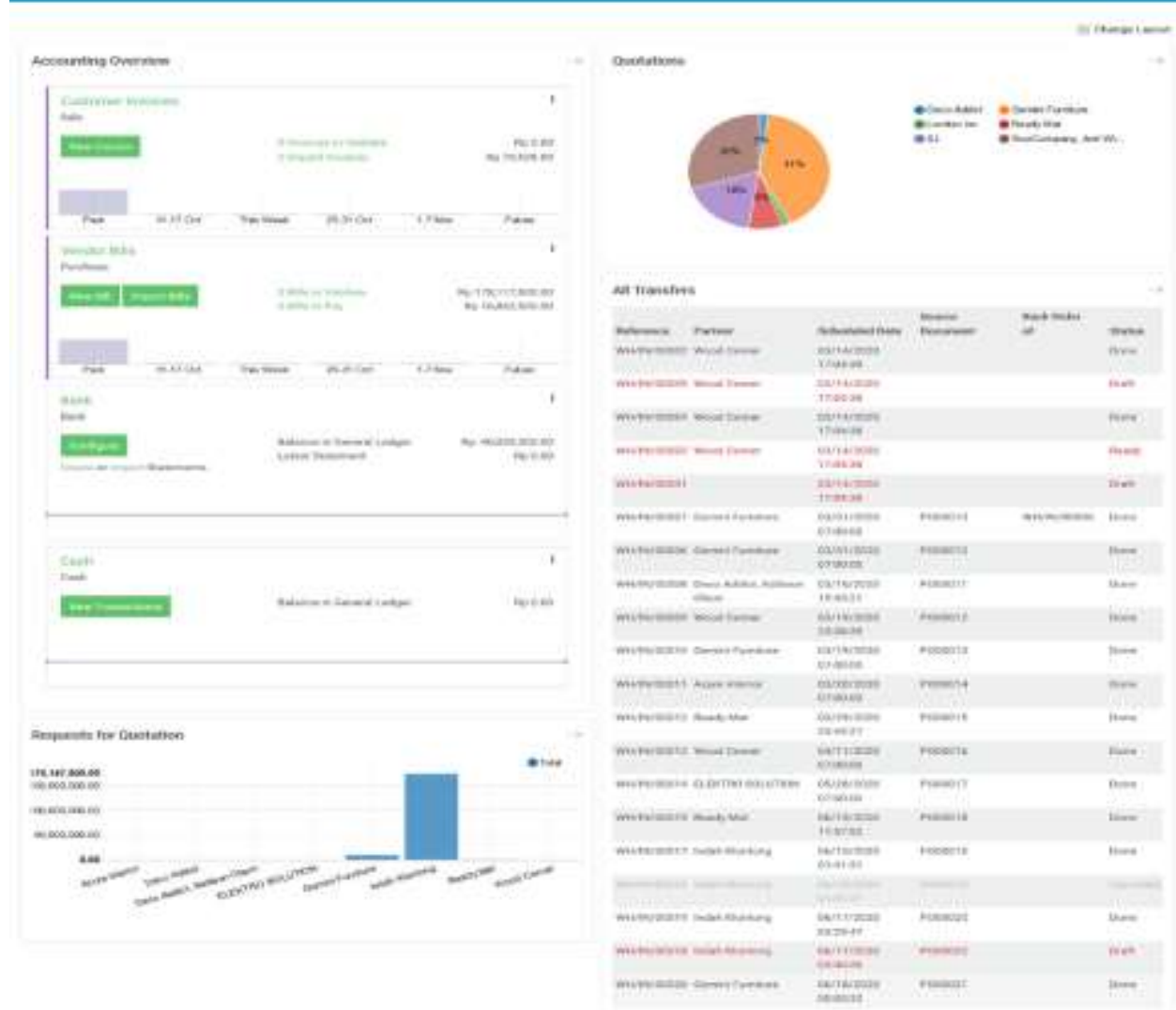

Gambar 14. Halaman Dashboard SCM Metrik SCOR

Pada menu ini menampilkan data keseluruhan dari sistem mengenai metode SCOR yang diimplementasikan pada sistem SCM PT Nieve Aplikasi Mandiri mulai dari sistem sales, purchasing, inventory, hingga accounting sehingga memudahkan atasan dalam melihat grafik dengan metrik SCOR dan permintaan yang terjadi pada perusahaan. 


\section{Kesimpulan}

Sistem Supply Chain Management membantu perusahaan dalam evaluasi kualitas dan kuantitas pengiriman barang ke customer. Dengan melakukan perhitungan menggunakan SCOR level 1 didapatkan POF $=72.28 \%$, OCFT $=15$ hari, $\mathrm{COGS}=49.07 \%$, CTCCT $=30$ hari dengan metode SCOR. Sehingga sangat merujuk sistem menyeluruh yang digunakan untuk mengelola melalui proses manufaktur sampai ke distribusi. Nilai komitmen dan kepercayaan pada perhitungan metrik sebelumnya menggunakan metode VCA mendapatkan hasil yang cukup baik, waktu yang dibutuhkan untuk response time pengiriman barang $\mathrm{Lt}^{\mathrm{sc}}=34.466$, sedangkan benefit dan cost $=0.530$. Dengan metode SCOR waktu yang dibutuhkan untuk response time permintaan hingga pengiriman hanya 15 hari, dan keuntungan yang didapatkan sebesar 49.07\%. Fitur yang ada pada sistem dapat mengklasifikasikan data dalam indikator SCOR sehingga hasil yang didapat menentukan penerapan keberhasilan SCM di PT Nieve Aplikasi Mandiri. Adapun saran untuk pengembangan sistem berikutnya adalah dengan pengembangan sistem menggunakan aplikasi mobile sehingga memudahkan penggunaannya.

\section{Referensi}

[1] F. R. Mawar Nurmaidah, Tacbir Hendro Pudjiantoro, "Pembangunan Sistem Manajemen Rantai Pasok dalam Proses Produksi Teh Di Pt. Perkebunan Nusantara Iii,” Vol. Xi, No. 1, Pp. $22-31$.

[2] R. U. F. Irawan Ricky,Witanti Wina, "Pembangunan Sistem Informasi Manajemen Rantai Pasok pada PT Garuda Mas Semesta," Prosiding Snatif Ke -5 Tahun 2018, Pp. 63-70, 2018.

[3] J. Hidayati and S. Hasibuan, "Value Chain Analysis and Value Added Enhancement of Indonesia Crude Palm Oil Supply Chain," International Journal on Advanced Science, Engineering and Information Technology, Vol. 9, No. 2, Pp. 397-404, 2019, Doi: 10.18517/Ijaseit.9.2.7708.

[4] S. Alfeno, W. H. Mulyo, and Raharja, "Pengembangan Prototype Supply Chain Management dengan Menggunakan Pendekatan External Value Chain," Jurnal Sisfotek Global, Vol. 5, No. $2,2015$.

[5] A. Nurhandayani and A. M. Noor, "Pengukuran Kinerja Rantai Pasok Cv. Vio Burger dengan Menggunakan Model Supply Chain Operation Reference (Scor) dan Metode Analytical Hierarchy Process (Ahp)," Jurnal Ilmiah Teknologi dan Rekayasa, Vol. 23, No. 3, Pp. 206219, 2018, Doi: 10.35760/Tr.2018.V23i3.2470.

[6] A. N. Waaly, A. Y. Ridwan, And M. D. Akbar, "Supply Chain Operation Reference (Scor) Model Dan Analytical Hierarchy Process (AHP) untuk Mendukung Green Procurement pada Industri Penyamakan Kulit," Journal Industrial Servicess, Vol. 4, No. 1, Pp. 1-6, 2018, Doi: 10.36055/Jiss.V4i1.4081.

[7] G. Prawesti, H. H. Purba, K. Iskandar, and T. A. Laksono, "Hubungan Antara Supply Chain Management dengan Supply Chain Responsiveness dan Competitive Advantage," Jurnal Teknik Industri, Vol. 6, No. 2, Pp. 153-157, 2016, Doi: 10.25105/Jti.V6i2.1539.

[8] D. Zulfikar And D. Ernawati, "Pengukuran Kinerja Supply Chain Menggunakan Metode Green Scor di Pt. XYZ," Juminten, Vol. 1, No. 1, Pp. 12-23, Jan. 2020, doi: 10.33005/Juminten.V1i1.3.

[9] S. Qrunfleh And M. Tarafdar, "Supply Chain Management Practices - It Utilisation Alignment: Impact on Supply Chain Performance and Firm Performance," International Journal Of Business Information Systems, Vol. 18, No. 4, Pp. 364-389, 2015, doi: 10.1504/Ijbis.2015.068476.

[10] Y. Jumaryadi, "Customer Complaint Information Systems at National Standardization of Indonesia," International Journal Information System and Computer Science (Ijiscs), Vol. 3, No. 2, Pp. 43-49, 2019.

[11] M. Munir, M. S. S. Jajja, K. A. Chatha, And S. Farooq, "Supply Chain Risk Management And Operational Performance: The Enabling Role of Supply Chain Integration," International Journal of Production Economics, Vol. 227, 2020, doi: 10.1016/J.Ijpe.2020.107667. 
[12] I. Nasrudin And R. Rivana, "Pengukuran Kinerja Supply Chain KPBS Pangalengan dengan Pendekatan Supply Chain Operation Reference (Scor) untuk Meningkatkan Produktivitas," Rekayasa Industri dan Mesin, Vol. 1, No. 1, Pp. 29-41, 2019.

[13] H. Padillah, Y. H. Chrisnanto, and A. Wahana, "Model Supply Chain Operation Reference (Scor) dan Analytic Hierarchy Process (AHP) Untuk Sistem Pengukuran Kinerja Supply Chain Management," Prosiding Snst, Pp. 31-36, 2016.

[14] N. Nurhasanah, W. N. Tanjung, E. Ripmiatin, S. A. Wulandari, M. Qibtiyah, and Meliantika, "Enhancing Competitiveness of Ready Made Garment Small-Medium Enterprises Through Logistics Performance Measurement using SCOR Method," 2016 2nd International Conference of Industrial, Mechanical, Electrical, and Chemical Engineering, ICIMECE 2016, pp. 123-126, 2017, doi: 10.1109/ICIMECE.2016.7910431. 